\title{
Delayed-onset interface fluid syndrome after LASIK following phacotrabeculectomy
}

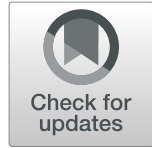

Chung Young Kim', Young Ho Jung ${ }^{2}$, Eun Ji Lee ${ }^{3^{*}} \mathbb{D}$, Joon Young Hyon ${ }^{3}$, Kyu Hyung Park ${ }^{3}$ and Tae Woo Kim

\begin{abstract}
Background: Interface fluid syndrome (IFS) is an unusual complication after laser-assisted in-situ keratomileusis (LASIK). We report the first case of IFS after uncomplicated phacotrabeculectomy in a patient who had undergone LASIK 10 years previously. This case emphasizes the importance of intraocular pressure (IOP) interpretation in eyes that have undergone LASIK.

Case presentation: A 30-year-old woman with a history of LASIK surgery presented to glaucoma clinic due to uncontrolled IOP despite of maximally tolerable medical treatment. After receiving phacotrabeculectomy, IOP decreased to $3 \mathrm{mmHg}$ on the first postoperative day, but again increased up to $21 \mathrm{mmHg}$ and a diffuse corneal edema with cloudy flap interface was demonstrated by slit-lamp microscopy. Corneal edema was sustained even after the IOP was lowered to $14 \mathrm{mmHg}$. Spectral-domain optical coherence tomography scanning of the cornea revealed a diffuse, thin fluid pocket in the corneal interface. After laser lysis of the scleral flap sutures, IOP was further decreased to $9 \mathrm{mmHg}$ and interface fluid was resolved.

Conclusion: IFS should be considered as a possible cause of postoperative corneal edema despite of low IOP in the eyes that underwent LASIK surgery. Additional IOP lowering may be helpful for resolving the corneal edema.
\end{abstract}

Keywords: Interface fluid syndrome, LASIK, Glaucoma, Phacotrabeculectomy

\section{Background}

Interface fluid syndrome (IFS) is an unusual complication after laser-assisted in-situ keratomileusis (LASIK) that is characterized by diffuse fluid accumulation within the flap interface. Although elevation of intraocular pressure (IOP) is the main sign associated with the IFS [1], falsely low IOP readings after LASIK could mimic the condition and delay an accurate diagnosis [2]. We report the first case of IFS after uncomplicated phacotrabeculectomy in a patient who had undergone LASIK 10 years previously. The IFS did not resolve when the IOP was reduced to within the statistically normal range, but it did resolve with further IOP reduction. This case emphasizes the importance of IOP interpretation in eyes that have undergone LASIK.

\footnotetext{
* Correspondence: opticdisc@gmail.com

${ }^{3}$ Department of Ophthalmology, Seoul National University Bundang Hospital, 300, Gumi-dong, Bundang-gu, Seongnam, Gyeonggi-do 13620, South Korea Full list of author information is available at the end of the article
}

\section{Case report}

A 30-year-old woman was presented to a glaucoma clinic due to uncontrolled IOP. She had undergone bilateral LASIK 10 years previously, and had been treated with oral and topical steroids as well as albendazole for 10 months for uveitis associated with ocular toxocariasis in the left eye. Sub-Tenon injection of triamcinolone acetonide $(40 \mathrm{mg})$ had also been performed 5 months previously.

At the first visit, her visual acuity was $20 / 200$ and the IOP was $30 \mathrm{mmHg}$ in the left eye measured by Goldmann applanation tonometry (GAT). Slit-lamp examination revealed Grade 1 posterior subcapsular opacity, and fundus examination showed glaucomatous change in the optic nerve head. Inflammatory cells were not detected in either the anterior or posterior chamber. Despite maximally tolerable medical treatment, the IOP subsequently increased up to $32 \mathrm{mmHg}$, and her visual acuity worsened to 20/500 with ongoing glaucomatous optic nerve damage and progression of posterior subcapsular opacity. Phacotrabeculectomy with topically applied mitomycin-C $(0.04 \%)$ was then performed. 


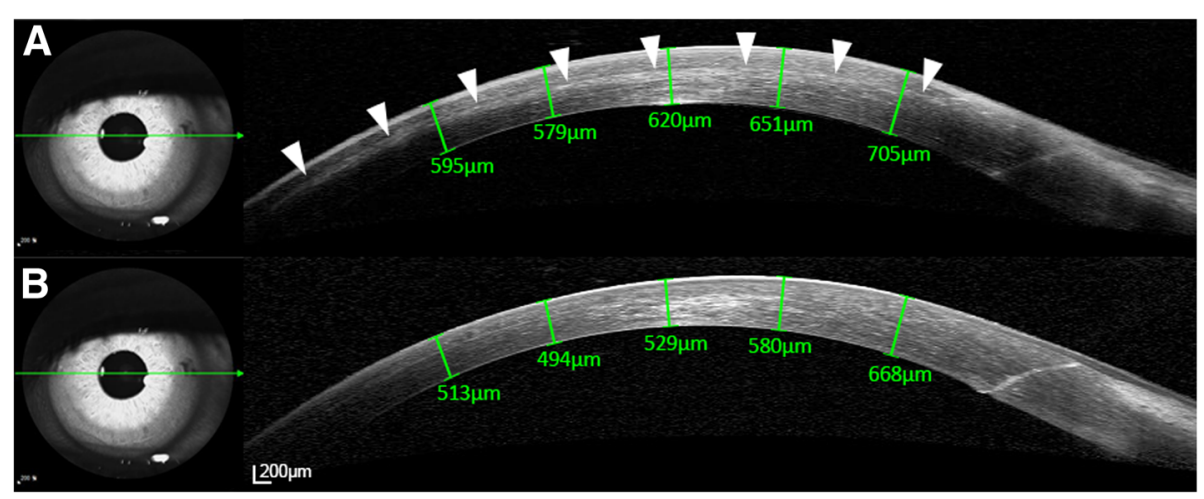

Fig. 1 Spectral-domain optical coherence tomography scanning of the cornea before (a) and after (b) performing suture lysis using an argon laser. Note that the diffuse and thin fluid pocket in the corneal interface region (arrowheads) resolved when the intraocular pressure was lowered from 14 to $9 \mathrm{mmHg}$

The IOP was $3 \mathrm{mmHg}$ by GAT on the first postoperative day but increased up to $21 \mathrm{mmHg}$ on the following day. Her visual acuity was hand movement and could not be corrected. A diffuse corneal edema with a cloudy flap interface was noted in a slit-lamp examination. At 1 week postoperatively, the IOP had decreased to $14 \mathrm{mmHg}$ after the application of brimonidine $(0.2 \%) /$ timolol $(0.5 \%)$ twice daily, but the corneal edema did not resolve. Spectral-domain optical coherence tomography (SD-OCT) scanning revealed a diffuse and thin fluid pocket in the corneal interface region (Fig. 1A). After using an argon laser to perform suture-lysis of the scleral flap on the following day, the IOP decreased to $9 \mathrm{mmHg}$ and the visual acuity improved to 20/150. Resolution of the interface fluid was noted by SD-OCT (Fig. 1B). Central corneal thicknesses were $553.5 \mu \mathrm{m}$ preoperatively and $576.6 \mu \mathrm{m}$ at 14 days postoperatively. Eight months postoperatively, the IOP was maintained at $8 \mathrm{mmHg}$ without using topical IOP-lowering agents, the cornea was clear without any interface haze by detailed slit-lamp examination, and the corrected visual acuity was 20/100.

\section{Discussions and conclusions}

Lowering of IOP commonly results in the resolution of interface fluid that can appear after LASIK [3]. However, the interface fluid in our case did not improve even when the IOP was reduced to within the statistically normal range; instead, a substantial IOP lowering down to a subnormal level was necessary for resolution of this fluid. We speculate that the decreased corneal thickness after LASIK and the ability of the accumulated fluid to absorb shock might have resulted in the underestimation of IOP [4]. This suggests that the target IOP should be lower in eyes that have undergone LASIK to allow for the possibility of falsely low IOP reading. In this case, IOP was measured at central cornea, but IOP measurement peripheral to the LASIK flap is also required for accuracy.
In eyes having a history of LASIK, the possibility of IFS should be considered as a possible cause of postoperative corneal edema even when the IOP is within normal range, particularly when the edema is long-standing and refractory to conventional treatment. An additional IOP lowering beyond the normal range may be helpful for resolving the corneal edema.

\section{Abbreviations \\ GAT: Goldmann applanation tonometry; IFS: Interface fluid syndrome; IOP: Intraocular pressure; LASIK: laser-assisted in-situ keratomileusis; SD- OCT: Spectral-domain optical coherence tomography}

Acknowledgments

None.

\section{Funding}

This study received no specific grant from any funding agency.

Availability of data and materials

All data and materials are available in this article.

\section{Authors' contributions}

CYK, YHJ, EJL, JYH, KHP and TWK contributed to conception and design, data acquisition and interpretation of data. CYK and YHJ drafted the article, and all authors approved the final version.

Ethics approval and consent to participate Not applicable.

Consent for publication

Written informed consent for this case report was obtained from the patient.

Competing interests

The authors declare that they have no competing interests.

\section{Publisher's Note}

Springer Nature remains neutral with regard to jurisdictional claims in published maps and institutional affiliations.

\section{Author details}

'Department of Ophthalmology, Seoul National University Hospital, Seoul, South Korea. ${ }^{2}$ 2nd Air Defense Missile Brigade, Republic of Korea Air Force, Gapyeong, South Korea. ${ }^{3}$ Department of Ophthalmology, Seoul National University Bundang Hospital, 300, Gumi-dong, Bundang-gu, Seongnam, Gyeonggi-do 13620, South Korea. 
Received: 17 December 2018 Accepted: 1 March 2019

Published online: 12 March 2019

\section{References}

1. Bamashmus MA, Saleh MF. Post-LASIK interface fluid syndrome caused by steroid drops. Saudi journal of ophthalmology : official journal of the Saudi Ophthalmological Society. 2013;27(2):125-8.

2. Duch S, Serra A, Castanera J, Abos R, Quintana M. Tonometry after laser in situ keratomileusis treatment. J Glaucoma. 2001;10(4):261-5.

3. Ortega-Usobiaga J, Martin-Reyes C, Llovet-Osuna F, Damas-Mateache B, Baviera-Sabater J. Interface fluid syndrome in routine cataract surgery 10 years after laser in situ keratomileusis. Cornea. 2012;31(6):706-7.

4. Han SB, Woo SJ, Hyon JY. Delayed-onset interface fluid syndrome after laser in situ keratomileusis secondary to combined cataract and vitreoretinal surgery. J Cataract Refract Surg. 2012;38(3):548-50.

Ready to submit your research? Choose BMC and benefit from:

- fast, convenient online submission

- thorough peer review by experienced researchers in your field

- rapid publication on acceptance

- support for research data, including large and complex data types

- gold Open Access which fosters wider collaboration and increased citations

- maximum visibility for your research: over $100 \mathrm{M}$ website views per year

At $B M C$, research is always in progress.

Learn more biomedcentral.com/submissions 